\title{
2006-1986: USING COMPUTATIONAL SOFTWARE ROOT SOLVERS: A NEW PARADIGM FOR PROBLEM SOLUTIONS?
}

\section{B. Hodge, Mississippi State University}

B. K. Hodge is Professor of Mechanical Engineering at Mississippi State University (MSU) where he serves as the TVA Professor of Energy Systems and the Environment and is a Giles Distinguished Professor and a Grisham Master Teacher. He is the author of more than 170 conference papers and archival journal articles and served as President of the American Society for Engineering Education (ASEE) Southeastern Section for the 1999-2000 Academic Year. He was the 2004-2005 Chair of the Mechanical Engineering Division of the ASEE at the national level.

\section{Rogelio Luck, Mississippi State University}

Rogelio Luck received the B.S. degree from Texas Tech University in 1984, and the M.S. and Ph.D. degrees from Penn State Univ., University Park, in 1987 and 1989, respectively, all in Mechanical Engineering. In 1989 he joined the faculty at the Mechanical Engineering Dept. at Mississippi State University where he has been an Associate Professor since 1994. His recent research interest is in the area of inverse heat transfer. 


\title{
Using Computational Software Root Solvers: A New Paradigm for Problem Solutions?
}

\begin{abstract}
Many of the "procedures" for solving engineering problems are formulations to solve an algebraic equation or a system of algebraic equations - to extract roots. Computational software systems, such as Mathcad, Mathematica, Matlab, and EES, make possible "direct" solutions of root-finding problems in which the solution procedure is transparent to the user. These computational systems permit a unified approach, a "new" paradigm, to be used for the solution to many engineering problems. The unified approach consists of three steps: (1) formulate a well-posed system of algebraic equations, (2) use a computational system root solver to do the "arithmetic," and (3) verify the results. This paper explores the use of the unified approach for mechanical engineering problems and investigates the pedagogical inferences of the unified approach using computational software systems for undergraduates in Mechanical Engineering. The unified approach permits the student to focus more on the engineering aspects than the "arithmetic" aspects. With less time spent on arithmetic, more time is available for students to engage is higher-level synthesis and understanding.
\end{abstract}

\section{Introduction}

Many of the "procedures" for solving engineering problems are formulations to solve an algebraic equation or a system of algebraic equations - to extract roots. In general, an algebraic equation can be linear or nonlinear and a system of algebraic equations can contain both linear and nonlinear algebraic equations. Recent computational software systems, such as Mathcad, Mathematica, Matlab, and EES, have made possible "direct" solutions of such problems in which the sometimes-laborious task, the procedure, of obtaining the solution is transparent to the user. Such equation or root solvers allow the students to concentrate on the engineering aspects of the problem, sparing them from being preoccupied by the details of finding the roots; i.e., solving the equations. The students can then focus their efforts on the engineering aspects of the problem by applying their engineering knowledge and skills to obtain a system of equations that represents the problem and that is sufficiently descriptive to provide a solution; i.e., to obtain a well-posed system of equations. An additional pedagogical advantage of using the root solvers is that the students are forced to discern whether the numerical (or symbolic) answers provided by the equation solvers are reasonable. Thus, the advent of such computational systems permits a unified approach, a "new" paradigm, to be used for the solution to many engineering problems. For appropriate problems, the unified approach consists of three steps: (1) formulate a well-posed system of non-linear algebraic equations, (2) use a computational system root solver to do the "arithmetic," and (3) verify the results.

Computational systems provide robust root solvers for systems of algebraic equations. Reference 1, from Desktop Engineering, presents a convenient summary of capabilities of the most commonly used computational systems. The "solve-block" structure in Mathcad, for example, 
requires the identification of the system of equations, values of the known quantities, and initial guessed values for the unknowns to obtain the solution. This is in stark contract to line-by-line coding of a root-solver procedure (Newton-Raphson, for instance) in a higher-level language (FORTRAN or $\mathrm{C}++$ ) to solve such a system.

The purposes of this paper are twofold: (1) to explore the use of the unified approach using computational software systems for mechanical engineering problems and (2) to investigate the pedagogical inferences of use of the unified approach with a computational software system in undergraduate mechanical engineering education. From a pedagogical standpoint, the unified approach permits the student to focus more on the engineering aspects, the formulation and validation, than the arithmetic aspects, and from an applications standpoint, the unified approach provides the student with a very useful addition to the student's engineering skill set.

Consider the following diverse examples using the computational system, Mathcad. All examples will be solved utilizing the three-step unified approach: (1) formulate the solution as a well-posed system of algebraic equations, (2) use the root solver to do the "arithmetic," and (3) verify the results. Example will be presented for an engineering economics problem, a vibrations problem, a pipe flow problem, and a cooling/bypass loop simulation. Although Mathcad is the computational software system used in this paper, other computational software systems possess similar capabilities and could be used equally well.

Examples

\section{$\underline{\text { Engineering Economics }}$}

A simple example to illustrate the unified approach is provided by the capital recovery factor of the present worth of a uniform series

$$
\frac{A}{P}=\frac{\frac{i}{m}\left(1+\frac{i}{m}\right)^{m n}}{\left(1+\frac{i}{m}\right)^{m n}-1}
$$

where $\mathrm{A}$ is the payment at intervals of $\mathrm{m}$ cycles during $\mathrm{n}$ years, $\mathrm{P}$ is the principal, and $\mathrm{i}$ is the interest rate per year. The quotient $\mathrm{A} / \mathrm{P}$ is the capital recovery factor. Tabular values of $\mathrm{A} / \mathrm{P}$ are provided in engineering economy textbooks, but the unified approach yields solutions without table interpolations. Consider the following example.

\section{Example 1:}

(a) For a 4-year, $\$ 20,000$ loan, what interest rate is required for monthly payments of $\$ 500$ ?

(b) How much could be borrowed at 6 percent interest and monthly payments of $\$ 500$ for 4 years?

\section{Solution:}

The solution is provided in Figure 1, the Mathcad worksheet. The solutions for Parts (a) and (b) are illustrated in Parts (a) and (b), respectively, of Figure 1. For both solutions, the solve block 
structure of Mathcad is used. The solve block is initiated by a Given and is terminated by a Find statement that specifies the unknowns. In this case, a single equation, Equation (1), with four variables is included within the solve block. The solve block can be used to solve for one of the variables, given the remaining three. Thus, Parts (a) and (b) of the problem are similar; the only difference being the variable specified in the Find statement. Essentially, all problems involving the present worth of a uniform series can be solved using this same solve block and specifying the appropriate unknown in the Find statement.

\section{Verification:}

Verification for this example consists of observing that for both parts of Example 1, the "numbers" are similar to what might be encountered in securing a car loan. The results are what might be expected, so the first verification test is that the results are not irrational. A more precise verification is provided in Part (c) of Figure 1. In Part (c) of the figure, a function, $A(i, P, m, n)$, expressing the functional relationship for the capital recovery factor of the present worth of a uniform series is defined and the results are verified by substituting $\mathrm{i}$ and $\mathrm{P}$, respectively, into the function to recover the monthly payment, A. In both cases, the function returns the appropriate value.

$$
\begin{array}{ll}
\mathrm{P}:=21000 & \mathrm{n}:=4 \quad \mathrm{~A}:=500 \quad \mathrm{~m}:=12 \quad \text { Define known quantities } \\
\mathrm{i}:=2 \% & \text { Initial guess on interest rate }
\end{array}
$$

Given

$$
\begin{aligned}
& \mathrm{A}=\mathrm{P} \cdot \frac{\frac{\mathrm{i}}{\mathrm{m}} \cdot\left(1+\frac{\mathrm{i}}{\mathrm{m}}\right)^{\mathrm{m} \cdot \mathrm{n}}}{\mathrm{m} \cdot \mathrm{n}} \\
& \left(1+\frac{i}{m}\right)^{m \cdot n}-1 \\
& \mathrm{i}:=\text { Find (i) } \quad \mathrm{i}=6.705 \%
\end{aligned}
$$

(a) Solution to Part (a)

$\mathrm{i}:=6 \% \quad \mathrm{n}:=4 \quad \mathrm{~A}:=500 \quad \mathrm{~m}:=12 \quad$ Define known quantities

$\mathrm{P}:=1000 \quad$ Initial guess on principal

Given

$$
\begin{gathered}
A=P \cdot \frac{\frac{i}{m} \cdot\left(1+\frac{i}{m}\right)^{m \cdot n}}{\left(1+\frac{i}{m}\right)^{m \cdot n}-1} \\
P:=\operatorname{Find}(P) \quad P=21290.159
\end{gathered}
$$

(b) Solution to Part (b)

Figure 1. Solutions for Example 1 


$$
\begin{array}{ll}
\mathrm{A}(\mathrm{i}, \mathrm{P}, \mathrm{m}, \mathrm{n}):=\mathrm{P} \cdot \frac{\frac{\mathrm{i}}{\mathrm{m}} \cdot\left(1+\frac{\mathrm{i}}{\mathrm{m}}\right)^{\mathrm{m} \cdot \mathrm{n}}}{\left(1+\frac{\mathrm{i}}{\mathrm{m}}\right)^{\mathrm{m} \cdot \mathrm{n}}-1} & \\
\mathrm{~A}(6.705 \%, 21000,12,4)=500.002 & \text { Part (a) } \\
\mathrm{A}(6 \%, 21290,12,4)=499.996 & \text { Part (b) }
\end{array}
$$

(c) Verification of Solutions

Figure 1. Solutions for Example 1 (Concluded).

\section{$\underline{\text { Vibrations }}$}

The normalized amplitude, Amp, of the vibration of the door panel of an automobile is given by

$$
A m p=\frac{1}{\sqrt{\left[1-\left(\frac{\omega}{\Omega_{f}}\right)^{2}\right]^{2}+c^{2} \cdot\left(\frac{\omega}{\Omega_{f}}\right)^{2}}}
$$

where $\mathrm{c}$ is the damping coefficient, $\omega$ is speed of the engine, and $\Omega_{\mathrm{f}}$ is the natural frequency of vibration of the door panel.

\section{Example 2:}

Find the speed of the engine for which the normalized amplitude is 2 for $\Omega_{\mathrm{f}}=20 \mathrm{~Hz}$.

\section{Solution:}

The solution steps are illustrated in Figure 2. Figure 2(a) is a Mathcad plot of the normalized amplitude as a function of motor speed in rpm. The function is double valued in rpm for a specified value of the normalized amplitude. The solution is presented in Figure 2(b). Part (a) of the figure indicates that a normalized amplitude of 2 occurs at about $750 \mathrm{rpm}$ and at about 1500 rpm. These values are used as initial guesses in the Mathcad solve block in Part (b) of Figure 2. The normalized amplitude function is defined and then used in the solve block. The solution results are $858 \mathrm{rpm}$ and $1453 \mathrm{rpm}$. Figure 2 indicated that the solution would be double valued in rpm. By specifying two initial guesses in the solve block, both values are returned. The user, thus, does not have to generate two separate solutions.

\section{Verification:}

The results presented in Figure 2(b) agree with the graphical representation in Figure 2(a).

\section{$\underline{\text { Pipe Flow }}$}

Piping systems are ubiquitous in engineering systems and are characterized as series, parallel, or network. Hodge ${ }^{2}$ explored the unified approach to solving a variety of piping systems problems. 


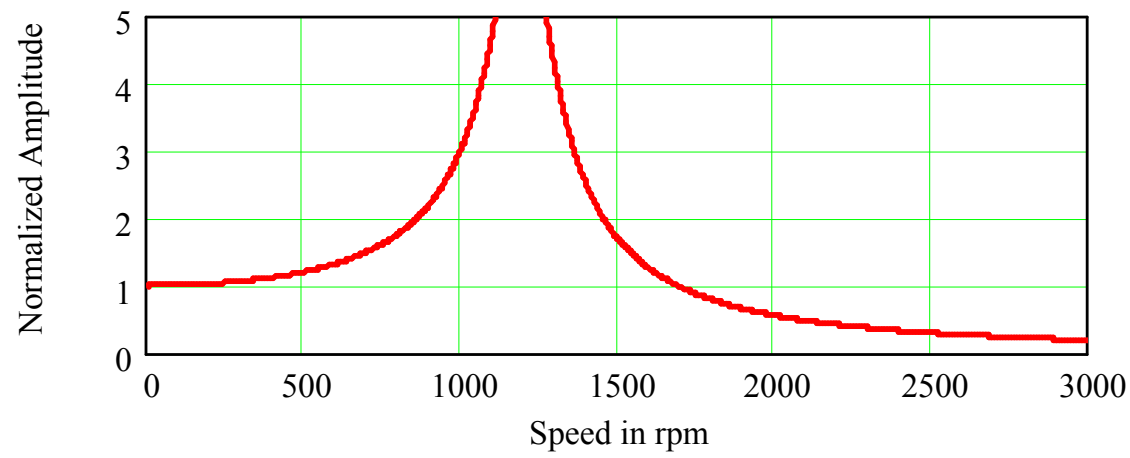

(a) Plot of Normalized Amplitude as a Function of Engine Speed (rpm)

$$
\begin{aligned}
& \operatorname{Amp}\left(\omega, \mathrm{c}, \Omega_{\mathrm{f}}\right):=\frac{1}{\sqrt{\left[1-\left(\frac{\omega}{\Omega_{\mathrm{f}}}\right)^{2}\right]^{2}+\mathrm{c}^{2} \cdot\left(\frac{\omega}{\Omega_{\mathrm{f}}}\right)^{2}}} \\
& \mathrm{c}:=0.15 \quad \mathrm{~Hz}:=60 \cdot \mathrm{rpm} \quad \Omega_{\mathrm{f}}:=20 \cdot \mathrm{Hz} \quad \omega:=\left(\begin{array}{c}
750 \\
1500
\end{array}\right) \cdot \mathrm{rpm} \quad \text { Initial Guesses }
\end{aligned}
$$

Given

$$
\begin{aligned}
2 & =\operatorname{Amp}\left(\omega, \mathrm{c}, \Omega_{\mathrm{f}}\right) \\
\text { Speed } & :=\text { Find }(\omega) \quad \text { Speed }=\left(\begin{array}{c}
89.887 \\
152.144
\end{array}\right) \mathrm{Hz} \quad \text { Speed }=\left(\begin{array}{c}
858.355 \\
1452.869
\end{array}\right) \mathrm{rpm}
\end{aligned}
$$

(b) Mathcad Solution

Figure 2. Solution for Example 2.

Included in Reference 2 are series, parallel, and network examples. The example presented herein is different from any of those in Reference 2.

The unified approach to piping systems uses the energy equation [Hodge and Taylor ${ }^{3}$, cast between two stations in a pipe with a pump as the fundamental building block,

$$
\frac{P_{A}-P_{B}}{\gamma}=Z_{B}-Z_{A}+\frac{V^{2}}{2 g}\left(f \frac{L}{D}+K+C \cdot f_{T}\right)-W_{s} \frac{g_{c}}{g}
$$

where $W_{s}$ is the increase in head of the pump and $\mathrm{K}$ and $\mathrm{C}$ are the minor loss coefficients. In addition, conservation of mass and uniqueness of pressure at a point are invoked. The conventional solution "procedures" developed for any characterization of piping problem satisfy these principles either by formally applying them in as part of the problem formulation or by using them in a specified iterative sequence - the "procedure." Solutions for all series, parallel, 
and network hydraulic piping problems can be formulated as solutions to a non-linear equation or to a system of nonlinear algebraic equations.

In Equation (1), expressions for the friction factor and fully rough friction factor, $\mathrm{f}_{\mathrm{T}}$, are needed. In the laminar regime, the usual expression is

$$
f=\frac{64}{\operatorname{Re}_{D}}
$$

Several different representations are available for turbulent flow. In this paper the representation of Haaland ${ }^{4}$ is used.

$$
f=\frac{0.3086}{\left[\log \left(\left(\frac{\varepsilon}{3.7 D}\right)^{1.11}+\frac{6.9}{\operatorname{Re}_{D}}\right)\right]^{2}}
$$

Minor loss terms are sometimes expressed as equivalent lengths using the fully-rough friction factor, $f_{T}$, the asymptotic value of the friction factor for a given relative roughness. From the Haaland equation, the fully-rough friction factor becomes

$$
f_{T}=\frac{0.3086}{\left[\log \left(\left(\frac{\varepsilon}{3.7 D}\right)^{1.11}\right)\right]^{2}}
$$

With the aforementioned as the basis for piping system problem solution formulation, an example of the unified approach will be examined and discussed.

\section{Example 3}

Water at $70 \mathrm{~F}$ is to be pumped from one reservoir to another reservoir located $20 \mathrm{ft}$ above the first reservoir. A pump with a characteristic curve (increase in head versus the flow rate)

$$
W_{s}=403.33-0.127 \cdot Q+0.004362 \cdot Q^{2}-0.00003911 \cdot Q^{3} \quad \text { for } \quad 0<Q<150 \mathrm{gpm}
$$

where $W_{s}$ is in $\mathrm{ft}-\mathrm{lbf} / \mathrm{lbm}$ when $Q$ is in gpm, is in the system. The system consists of $2000 \mathrm{ft}$ of schedule 40 nominal 3-inch commercial steel pipe. Minor losses total $\mathrm{K}=1000$ and $\mathrm{C}=0$. Find the flow rate the pump will produce in the system.

\section{Solution:}

The unified approach solution is provided in Figure 3. Much of the contents of the figure are specifying the system boundary conditions, the physical properties, the friction factor representation, and the units. As with the other examples, the solution is accomplished in the solve block. Prior to the solve block specification, initial estimates of the two unknowns, the pump increase in head and the flow rate, are provided. The pump characteristic equation, with appropriate units is defined as is the energy equation for the system. The Find statement contains the two unknowns. The pump increase in head and the flow rate, the pump-system operating point, are $393 \mathrm{ft}-\mathrm{lbf} / \mathrm{lbm}$ and $105 \mathrm{gpm}$, respectively. A similar worksheet can be used to solve all series hydraulic piping problems by suitably modifying the solve block and the Find statement. 
ORIGIN $\equiv 1 \quad$ Reset counter from the default value of 0 to 1 .

Input the pipe geometry:

Diameter in inches Length in feet Roughness in feet:
$\mathrm{D}:=3.068 \mathrm{in}$
$\mathrm{L}:=2000 \mathrm{ft}$
$\varepsilon:=0.00015 \mathrm{ft}$

Input the system boundary (initial and end) conditions:

Pressures in psi Elevations in feet:

$$
\left(\begin{array}{c}
\mathrm{P}_{\mathrm{a}} \\
\mathrm{P}_{\mathrm{b}}
\end{array}\right):=\left(\begin{array}{l}
0 \\
0
\end{array}\right) \cdot \frac{\mathrm{lbf}}{\text { in }^{2}} \quad\left(\begin{array}{c}
\mathrm{Z}_{\mathrm{a}} \\
\mathrm{Z}_{\mathrm{b}}
\end{array}\right):=\left(\begin{array}{c}
0 \\
20
\end{array}\right) \cdot \mathrm{ft}
$$

Input the loss coefficients:

$$
\begin{array}{cc}
\mathrm{K} \text { factor } & \text { Equivalent length } \\
\mathrm{K}:=1000 & \mathrm{C}:=0
\end{array}
$$

Input the fluid properties:

Density in lbm/ft ${ }^{3}$

Viscosity in lbm/ft-s

$$
\rho:=62.3 \cdot \frac{\mathrm{lb}}{\mathrm{ft}^{3}} \quad \mu:=0.000658 \frac{\mathrm{lb}}{\mathrm{ft} \cdot \mathrm{sec}}
$$

Define constants and adjust units for consistency:

$$
\mathrm{g}:=32.174 \frac{\mathrm{ft}}{\mathrm{sec}^{2}} \quad \mathrm{~g}_{\mathrm{c}}:=32.174 \frac{\mathrm{ft} \cdot \mathrm{lb}}{\mathrm{lbf} \cdot \mathrm{sec}^{2}}
$$

Define the functions for Reynolds number, fully-rough friction factor, and friction factor:

$$
\begin{aligned}
& \operatorname{Re}(\mathrm{q}, \mathrm{d}):=\frac{4 \cdot \rho \cdot \mathrm{q}}{\pi \cdot \mathrm{d} \cdot \mu} \quad \mathrm{f}_{\mathrm{T}}(\mathrm{d}, \varepsilon):=\frac{0.3086}{\log \left[\left(\frac{\varepsilon}{3.7 \cdot d}\right)^{1.11}\right]^{2}} \\
& \mathrm{f}(\mathrm{q}, \mathrm{d}, \varepsilon):=\mid \frac{0.3086}{\log \left[\frac{6.9}{\operatorname{Re}(\mathrm{q}, \mathrm{d})}+\left(\frac{\varepsilon}{3.7 \cdot \mathrm{d}}\right)^{1.11}\right]^{2}} \text { if } \operatorname{Re}(\mathrm{q}, \mathrm{d})>2300 \\
& \frac{64}{\operatorname{Re}(\mathrm{q}, \mathrm{d})} \text { otherwise }
\end{aligned}
$$

Figure 3. Mathcad Solution for Problem 3. 


$$
\begin{array}{ll}
\mathrm{W}_{\mathrm{S}}:=100 \cdot \mathrm{ft} \cdot \frac{\mathrm{lbf}}{\mathrm{lb}} & \begin{array}{l}
\text { (Initial guess of pump increase in head.) } \\
\mathrm{Q}:=50 \cdot \frac{\mathrm{gal}}{\mathrm{min}}
\end{array} \quad \text { (Initial guess of flow rate.) } \mathrm{gpm}:=\frac{\mathrm{gal}}{\mathrm{min}}
\end{array}
$$

Given

$$
\begin{aligned}
& \mathrm{W}_{\mathrm{S}}=\left[403.33-0.127 \cdot \frac{\mathrm{Q}}{\mathrm{gpm}}+0.004362\left(\frac{\mathrm{Q}}{\mathrm{gpm}}\right)^{2}-0.00003911\left(\frac{\mathrm{Q}}{\mathrm{gpm}}\right)^{3}\right] \cdot \frac{\mathrm{ft} \cdot \mathrm{lbf}}{\mathrm{lb}} \\
& \mathrm{W}_{\mathrm{s}} \cdot \frac{\mathrm{g}_{\mathrm{c}}}{\mathrm{g}}=\frac{\mathrm{P}_{\mathrm{b}}-\mathrm{P}_{\mathrm{a}}}{\rho \cdot \mathrm{g}} \cdot \mathrm{g}_{\mathrm{c}}+\mathrm{Z}_{\mathrm{b}}-\mathrm{Z}_{\mathrm{a}}+\frac{8}{\pi^{2}} \cdot \frac{\mathrm{Q}^{2}}{\mathrm{~g} \cdot(\mathrm{D})} \cdot\left(\mathrm{f}(\mathrm{Q}, \mathrm{D}, \varepsilon) \cdot \frac{\mathrm{L}}{\mathrm{D}}+\mathrm{K}+\mathrm{C} \cdot \mathrm{f}_{\mathrm{T}}(\mathrm{D}, \varepsilon)\right) \\
& \left(\begin{array}{c}
\mathrm{W}_{\mathrm{s}} \\
\mathrm{Q}
\end{array}\right):=\operatorname{Find}\left(\mathrm{W}_{\mathrm{s}}, \mathrm{Q}\right) \quad \mathrm{W}_{\mathrm{s}}=392.868 \mathrm{ft} \cdot \frac{\mathrm{lbf}}{\mathrm{lb}} \quad \mathrm{Q}=104.887 \frac{\mathrm{gal}}{\mathrm{min}}
\end{aligned}
$$

(a) Solution

$$
\begin{aligned}
\mathrm{PW}_{\mathrm{s}}:= & {\left[403.33-0.127 \cdot \frac{\mathrm{Q}}{\mathrm{gpm}}+0.004362\left(\frac{\mathrm{Q}}{\mathrm{gpm}}\right)^{2}-0.00003911\left(\frac{\mathrm{Q}}{\mathrm{gpm}}\right)^{3}\right] \cdot \frac{\mathrm{ft} \cdot \mathrm{lbf}}{\mathrm{lb}} } \\
& \mathrm{PW}_{\mathrm{s}}=392.868 \mathrm{ft} \cdot \frac{\mathrm{lbf}}{\mathrm{lb}} \\
\mathrm{EW}_{\mathrm{s}}:= & {\left[\frac{\mathrm{P}_{\mathrm{b}}-\mathrm{P}_{\mathrm{a}}}{\rho \cdot \mathrm{g}} \cdot \mathrm{g}_{\mathrm{c}}+\mathrm{Z}_{\mathrm{b}}-\mathrm{Z}_{\mathrm{a}}+\frac{8}{\pi^{2}} \cdot \frac{\mathrm{Q}^{2}}{\mathrm{~g} \cdot(\mathrm{D})} \cdot\left(\mathrm{f}(\mathrm{Q}, \mathrm{D}, \varepsilon) \cdot \frac{\mathrm{L}}{\mathrm{D}}+\mathrm{K}+\mathrm{C} \cdot \mathrm{f}_{\mathrm{T}}(\mathrm{D}, \varepsilon)\right)\right] } \\
& \mathrm{EW}_{\mathrm{S}}=392.868 \mathrm{ft}
\end{aligned}
$$

(b) Verification

Figure 3. Mathcad Solution for Problem 3 (Concluded).

\section{Verification:}

The first point of verification is that the flow rate, $105 \mathrm{gpm}$, falls within the specified flow rate range of the pump. In Part (b) of Figure 3 the increase in head of the pump, $P W_{s}$, is computed from the pump characteristic curve given the operating point flow rate. The energy equation increase in head requirement, $E W_{s}$, is also computed. Both values are identical and are equal to the returned value, $W_{s}$, of the solution.

\section{$\underline{\text { System Simulation }}$}

Systems of algebraic equations arise naturally in many steady-state system simulations. The use of computational system root solvers alleviates considerable programming effort and permits the student to concentrate on the engineering aspects of the problem. Consider the following thermal system simulation example.

\section{Example 4:}

Characteristics and specifications for an oil cooler system are delineated below. A system schematic is provided in Figure 4. 


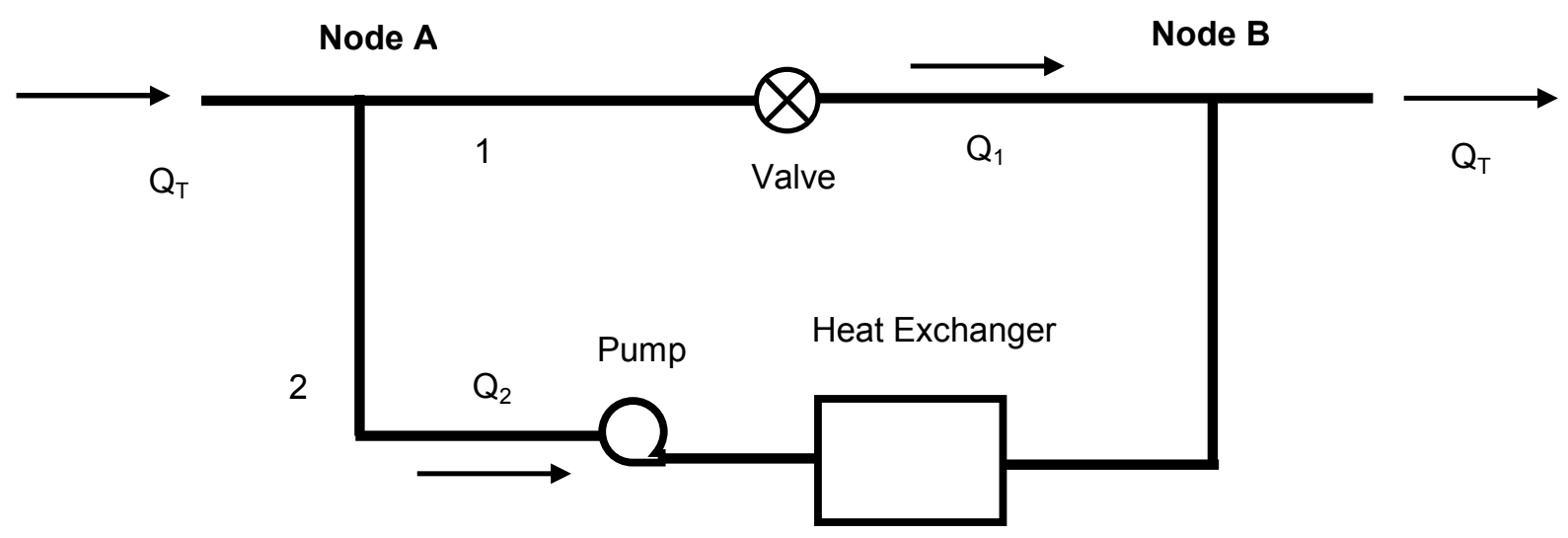

Figure 4. Schematic for Oil Cooler System.

System characteristics:

$\begin{array}{ccc}\text { Line } & \mathrm{D}(\mathrm{sch} \text { 40) } & \mathrm{L}(\mathrm{ft}) \\ 1 & 31 / 2 \text { in } & 100 \\ 2 & 31 / 2 \text { in } & 200\end{array}$

Oil properties (constant): $\quad \rho=54.3 \mathrm{lbm} / \mathrm{ft}^{3}$

$v=9.8 \times 10^{-5} \mathrm{ft}^{2} / \mathrm{sec}$

$\mathrm{c}=0.48 \mathrm{Btu} / \mathrm{lbm}-\mathrm{F}$

$\mathrm{T}_{\text {in }}=200 \mathrm{~F}$

Pump characteristic curve: $\quad \mathrm{W}_{\mathrm{s}}=214.2+0.05 \mathrm{Q}-0.0005833 \mathrm{Q}^{2} \quad(\mathrm{Q}$ in gpm)

Water properties: $\quad$ mass flow rate $=30 \mathrm{lbm} / \mathrm{sec}$

$\mathrm{T}_{\mathrm{in}}=70 \mathrm{~F}$

Heat Exchanger:

$$
\begin{aligned}
& \mathrm{A}=400 \mathrm{ft}^{2} \\
& \mathrm{HX}=0.0045 \mathrm{Q}^{1.9}
\end{aligned}
$$

Determine the exit temperature of the oil.

\section{Solution:}

This solution to this system simulation problem involves both hydraulic and thermal considerations. If constant thermophysical properties are considered, the hydraulic and thermal solutions can be decoupled and the exit temperature calculated after the individual pipe flow rates are known. In this example, both the hydraulic and thermal portions will be worked in a single solve block. Lines 1 and 2 form a parallel network, so the total change in head for pipe 1 must be equal to the total change in head for pipe 2. The energy equation, as referenced in Example 3, is used to describe the changes in heads of the individual pipes. Once the pipe flow 
rates are known, the temperature of the oil exiting the heat exchanger can be determined. The determination of the temperature of the oil exiting the heat exchanger is a heat exchanger analysis problem and proceeds from capacity to NTU to effectiveness to rating to exit temperature. An energy balance must be performed at node B to determine the exit temperature of the oil at it leaves the system. An energy balance at node B yields

$$
T_{\text {exit }}=\frac{Q_{1}}{Q_{T}} \cdot T_{1}+\frac{Q_{2}}{Q_{T}} \cdot T_{2}
$$

Figure 5 delineates the Mathcad worksheet for the problem solution. The solve block contains 13 equations and the Find function is used to determine the 13 unknowns. The exit temperature for the conditions of the problem statement is $151.6 \mathrm{~F}$. Other values of important variables are also presented in the figure.

\section{Verification:}

The solution values are all reasonable. If the individual equations describing the system are evaluated, all values are consistent.

\section{Pedagogical Inferences and Conclusions}

One purpose of this paper is to discuss a unified approach to solving many problems of engineering interest. In all the examples explored in this paper, the same three steps are used. The treatments of all the example problems are identical and emphasize the three steps: (1) formulate a well-posed system of algebraic equations, (2) use the root solver to do the "arithmetic," and (3) verify the results. The arithmetic has been accomplished by using the Solve-Find structure of Mathcad. Other computational software systems (Mathematics, Matlab,....) offer the same capability, albeit in different formats, but with the same results.

The second purpose of this paper is to examine the pedagogical inferences of undergraduates routinely using structured root solvers in a Mechanical Engineering (ME) program. For nearly a decade the ME program at Mississippi State University (MSU) has used Mathcad as the computational tool for undergraduate (and some graduate) ME courses. The observations and inferences made in this paragraph are all anecdotal. Faculty response has been uniformly enthusiastic. Indeed, one faculty member remarked that Mathcad has made his courses much more fun - for both teacher and student. The impact of Mathcad on a required ME energy systems design course at MSU was examined in Hodge ${ }^{5}$. In that paper, he concluded that the use of Mathcad permitted more realistic design problems to be assigned since the student effort required to debug/modify a Mathcad-based solution was less than the time required to debug a Fortran or C++ program. The use of solve blocks, such as the pipe flow solution in Example 3, comprised an important component in the energy systems design course.

One area of pedagogical concern expressed by faculty members about using structured solvers for an algebraic equation or systems of algebraic equations is that students no longer have an indepth understanding of the procedures required to solve a particular problem. This is a legitimate concern, but the same concern could be raised by many "new" techniques driven by computer capability and availability. The students do not need to possess extensive expertise in 
"procedures" that have been replaced by more time-effective techniques - the solve block in this discussion. Some MSU ME faculty have observed that by emphasizing the formulation of a well-posed system of equations using fundamental principles that students have become more competent with the "physics" of the problem and more able to transfer that competence to other situations. In an informal survey of MSU ME students concerning the use of the Mathcad solve block procedure discussed in this paper, students often commented that the emphasis on problem formulation required by the solve block had strengthened their understanding of the basic principles. Students also realize the time and effort saved by using the computational systems since in some courses the traditional approaches are still used. The students appreciate the attention to problem solution using the three-step unified approach.

The use of Mathcad with its Solve-Find structure relieves the student from assimilating different numerical techniques ("procedures") to solve a non-linear equation or a system of non-linear equations. The net result is that more involved and more realistic problems can be assigned. With less time spent on arithmetic, more time is available for students to engage is higher-level synthesis and understanding.

\section{References}

1. ___ 2003, "Mathematics Software Guide,” Desktop Engineering, July, pp. 32-33.

2. Hodge, B. K., 2006, “A Unified Approach to Piping System Problems," ASEE Computers in Education Journal, to appear in Vol. 2.

3. Hodge, B. K., and Taylor, R. P., 1999, Analysis and Design of Energy Systems, $3^{\text {rd }}$ ed, Prentice-Hall, Upper Saddle River, NJ.

4. Haaland, S. E., 1983, "Simple and Explicit Formulas for the Friction Factor in Turbulent Flow," Trans. ASME, J. of Fluids Engineering, Vol. 103, No. 5, pp. 89-90.

5. Hodge, B. K., 1998, “The Evolution of a Required Energy Systems Design Course,” ASME Paper 98-WA/DE-9 presented at the 1998 ASME International Mechanical Engineering Congress and Exposition, Anaheim, CA.

Initial guesses for the unknowns are needed to use the solve block.

$$
\begin{array}{llll}
\mathrm{Q}_{1}:=125 \cdot \frac{\mathrm{gal}}{\mathrm{min}} & \mathrm{Re}_{1}:=100000 & \mathrm{C}_{\min }:=5 \cdot \frac{\mathrm{BTU}}{\mathrm{sec} \cdot \mathrm{R}} & \mathrm{K}:=2.85 \\
\mathrm{Q}_{2}:=125 \cdot \frac{\mathrm{gal}}{\mathrm{min}} & \mathrm{Re}_{2}:=100000 & \mathrm{C}:=\frac{\mathrm{C}_{\min }}{\mathrm{C}_{\max }} & \xi:=0.5 \\
\mathrm{HP}:=216 \mathrm{ft} & \mathrm{HX}:=216 \mathrm{ft} & \mathrm{NTU}:=2 & \mathrm{gpm}:=\frac{\mathrm{gal}}{\mathrm{min}} \\
\mathrm{U}:=10 \cdot \frac{\mathrm{BTU}}{\mathrm{hr} \cdot \mathrm{ft}^{2} \cdot \mathrm{R}} & \mathrm{T}_{\text {out }}:=130 \cdot \mathrm{F} & \mathrm{T}_{\text {exit }}:=190 \cdot \mathrm{F} &
\end{array}
$$

Figure 5. Solution of System Simulation Example. 
The solve block equations are next defined.

Given

$$
\begin{aligned}
& \mathrm{Q}_{\mathrm{T}}=\mathrm{Q}_{1}+\mathrm{Q}_{2} \quad \mathrm{Re}_{1}=\frac{\mathrm{Q}_{1}}{\mathrm{~A}_{\mathrm{c}}} \cdot \frac{\mathrm{ID}}{\mathrm{v}} \quad \mathrm{Re}_{2}=\frac{\mathrm{Q}_{2}}{\mathrm{~A}_{\mathrm{c}}} \cdot \frac{\mathrm{ID}}{\mathrm{v}} \\
& \mathrm{HX}=0.0045 \mathrm{ft} \cdot\left(\frac{\mathrm{Q}_{2}}{\mathrm{gpm}}\right)^{1.9} \\
& \mathrm{HP}=214.2 \cdot \mathrm{ft}+0.05 \cdot \mathrm{ft} \cdot \frac{\mathrm{Q}_{2}}{\mathrm{gpm}}-0.0005833 \mathrm{ft} \cdot\left(\frac{\mathrm{Q}_{2}}{\mathrm{gpm}}\right)^{2} \\
& \frac{1}{2 \cdot g \cdot A_{c}{ }^{2}} \cdot\left(Q_{1}\right)^{2} \cdot\left(K+f_{f}\left(R_{1}\right) \cdot \frac{L_{1}}{I D}\right)=\frac{1}{2 \cdot g \cdot A_{c}{ }^{2}} \cdot\left(Q_{2}\right)^{2} \cdot f_{f}\left(R_{2}\right) \cdot \frac{L_{2}}{I D}+H X-H P \\
& \mathrm{C}_{\min }=\mathrm{Q}_{2} \cdot \rho_{\text {oil }} \cdot \mathrm{c}_{\text {oil }} \quad \mathrm{C}=\frac{\mathrm{C}_{\min }}{\mathrm{C}_{\max }} \\
& \mathrm{U}=\frac{\frac{\mathrm{BTU}}{\mathrm{hr} \cdot \mathrm{ft}^{2} \cdot \mathrm{R}}}{\left(\frac{5.75}{\mathrm{Re}_{2}{ }^{0.8}}\right)+0.004} \quad \mathrm{NTU}=\frac{\mathrm{U} \cdot \mathrm{A}_{\mathrm{hx}}}{\mathrm{C}_{\mathrm{min}}} \\
& \xi=\frac{1-\exp [-\mathrm{NTU} \cdot(1-\mathrm{C})]}{1-\mathrm{C} \cdot \exp [-\mathrm{NTU} \cdot(1-\mathrm{C})]} \quad \mathrm{T}_{\mathrm{out}}=\mathrm{T}_{\text {in }}-\xi \cdot\left(\mathrm{T}_{\text {in }}-\mathrm{T}_{\mathrm{water}}\right) \\
& \mathrm{T}_{\text {exit }}=\frac{\mathrm{Q}_{1}}{\mathrm{Q}_{\mathrm{T}}} \cdot \mathrm{T}_{\text {in }}+\frac{\mathrm{Q}_{2}}{\mathrm{Q}_{\mathrm{T}}} \cdot \mathrm{T}_{\text {out }} \\
& \text { ans := Find }\left(\mathrm{Q}_{1}, \mathrm{Q}_{2}, \mathrm{HX}, \mathrm{HP}, \mathrm{Re}_{1}, \mathrm{Re}_{2}, \mathrm{C}_{\mathrm{min}}, \mathrm{C}, \mathrm{U}, \mathrm{NTU}, \xi, \mathrm{T}_{\text {out }}, \mathrm{T}_{\text {exit }}\right) \\
& \mathrm{Q}_{1}:=\text { ans } 0 \quad \mathrm{Q} 1=189.142 \frac{\mathrm{gal}}{\mathrm{mir}} \quad \mathrm{NTU}:=\text { ans9 } \quad \mathrm{NTU}=1.284 \\
& \mathrm{Q}_{2}:=\text { ans } 1 \quad \mathrm{Q}_{2}=260.858 \frac{\mathrm{gal}}{\mathrm{mir}} \quad \xi:=\text { ans } 10 \quad \xi=0.642 \\
& \mathrm{C}:=\text { ans7 } \quad \mathrm{C}=0.505 \quad \mathrm{~T}_{\text {out }}:=\text { ans } 11 \quad \mathrm{~T}_{\text {out }}=116.532 \mathrm{~F} \\
& \mathrm{U}:=\text { ans8 } \quad \mathrm{U}=175.017 \frac{\mathrm{BTU}}{\mathrm{hr} \cdot \mathrm{ft}^{2} \mathrm{R}} \quad \mathrm{T}_{\text {exit }}:=\text { ans } 12 \quad \mathrm{~T}_{\text {exit }}=151.615 \mathrm{~F}
\end{aligned}
$$

Figure 5. Solution of System Simulation Example (Concluded). 